ISBN 978-93-84422-76-9

6th International Conference on Developments in Engineering and Technology

(ICDET-2017)

Bangkok (Thailand) Feb.6-7, 2017

\title{
Simulation And Experimental Determination Of Weld Bead Characteristics Of FRICTION STIR WELDING On Similar And Dissimilar AA6061 And AA5083 Aluminium Alloys
}

\begin{abstract}
Dr. Lingaraju Dumplala ${ }^{1}$, and Laxmanaraju salavaravu ${ }^{2}$
${ }^{1}$ Department of Mechanical Engineering, University College of Engineering, JNTUK, Kakinada, Andhra Pradesh, India.+91-9247793403, dlraju@gmail.com

Abstract: Friction Stir Welding (FSW) is fairly a recent technique that uses a non-consumable rotating welding tool to generate frictional heat and plastic deformation at the welding location while the material is in solid state. In this thesis, AA6061-T6, AA5083 of each 6 mm thickness plates are fabricated Butt joint by friction stir welding with different process parameters. The process parameters of spindle speeds are 800, 1000 and $1200 \mathrm{rpm}$. Welding speeds are 05, 10, 20 and $30 \mathrm{~mm} / \mathrm{min}$. A taper threaded H13 steel tool is used. For welding the mechanical properties of weld joints obtained from welding both the similar and dissimilar material fabrication are compared. The mechanical properties include tensile test, Brinell hardness test, and impact test and surface roughness measurement. Simulation of friction stir welding processes was carried out in Deform 3D software, in order to understand the changes in the welding process under the different process parameters. In order to defense with the obtaining results they are validate by using DEFORM-3D simulation software. By using this simulation only the temperatures were represented in this investigation.\& Manufacturing Engineering, etc.
\end{abstract}

Keywords: Friction Stir Welding (FSW), Deform-3D, weld bead, mechanical properties, simulation

\section{Introduction}

Friction-stir welding (FSW) is a solid-state joining process the metal is not melted that uses a third body tool to join two facing surfaces. Heat is generated between the tool and material which leads to a very soft region near the FSW tool. It then mechanically inter the two pieces of metal at the place of the joint, then the softened metal due to the elevated temperature can be joined using mechanical pressure which is applied by the tool, much like joining clay, or dough. It is primarily used on aluminium, and most often on extruded aluminium like non-heat treatable alloys, and on structures which need superior weld strength without a post weld heat treatment FSW is to create a high quality welded joints. Primarily FSW is used to weld for aluminum alloys. The process is carried out by plunging a rotating tool made of a wear-resistant and high temperature resistant material that is converted into the material to be joined and translated it along the desired weld line. Heat is generated between the tool and material which leads to a very soft region near the FSW tool. In this FSW process the tool material must be harder than the work piece material. Tool geometry has a great influence on resulting mechanical properties of the weld. It provides in-situ heating, stirs base material, and thus creates weld. There has been variety of tool shapes used. FSW can be performed with a tool of a simple geometry having good mechanical properties .Advanced tool design provides intensified material flow in the stirred zone and better weld quality.

The Researchers have developed a 3D visco-plastic model of FSW to estimate temperature history and material flow and validated the same with experimental data. They have assumed the material as a nonNewtonian fluid and allowed the flow stress to vary as a function of temperature and strain rate some of the investigators have done a 3D analysis of FSW in DEFROM 3D to predict temperature history and strain profile during welding. DEFORM can be used to analyze most thermo-mechanical forming processes, and many heat 
treatment processes. The general approach is to define the geometry and materials of the initial workpiece in DEFORM, and then sequentially simulate each process that is to be applied to the workpiece.

\section{Literature Review}

The joining of dissimilar AA2024 and AA6061 aluminium plates of 5mm thickness was carried out by friction stir welding (FSW) in his investigation [1]. Effect of welding speed on microstructures, hardness distribution and tensile properties of the welded joints were investigated. By varying the process parameters, defect free and high efficiency welded joints were produced. The ratio between tool shoulder diameter and pin diameter is the most dominant factor. The hardness in the HAZ of 6061 was found to be minimum, where the welded joints failed during the tensile studies. [2] The joining of dissimilar Al-Cu alloy AA2219-T87 and AlMg alloy AA5083-H321 plates was carried out using friction stir welding (FSW) technique. The rotational speed, transverse speed, tool geometry and ratio between tool shoulder diameter and pin diameter were the parameters taken into consideration. The predicted optimal value of tensile strength was confirmed. This study shows that defect free, high efficiency welded joints can be produced using a wide range of process parameters and recommends parameters for producing best joint tensile properties.[3] investigated the Mechanical and metallurgical characterization of FSW joints of AA6061-T6 with AA6082-T6. In tensile tests the dissimilar joint displayed intermediate properties. The mechanical characterization of friction stir welding of aluminium alloy 6061-T6 with 6082-T6 was carried out. For comparison, similar joints made from each of the two alloys were also performed. The selected parameters were travel speed of $224 \mathrm{~mm} / \mathrm{min}$; tilt angle of 2.5, rotating speed of 1120rpm. M5 threaded pin shoulder was smooth and 7 concave with $17 \mathrm{~mm}$ diameter. Micro hardness tests were performed in order to characterize the hardness profile in the vicinity of the weld affected area. In the tensile tests, failures occurred near the weld edge line where a minimum value of hardness was observed. [4] investigated a study of process parameters of friction stir welded AA 6061 aluminium alloy in t6 conditions plates. The material of the tool is H11 tool steel. The tool has frustum shaped probe with threads. The evaluation of mechanical properties at room temperature i.e., tensile strength, bend property in pre weld and post weld heat treatment conditions is done. Micro structural analysis is done by optical microscopy. In this nugget zone long grains are observed it contains sub grains, sub-boundaries and dislocations. It is completely dependent upon the shape of tool pin of FSW. So it can be concluded that in annealed condition tool rotation speed $800 \mathrm{rpm}$ and welding speed $10 \mathrm{~mm} / \mathrm{min}$ and $15 \mathrm{~mm} / \mathrm{min}$ are the optimal parameters. The effect of different parameters on the mechanical properties of the butt welded joint AA6061 is analysed. [5] The mechanical properties of 6082 T6 friction stir welded butt joints were investigated in the AS FSW state and after a post-welding heat treatment at $535^{\circ} \mathrm{C}$ for 2 hours. Tensile tests and micro hardness measurements were conducted on butt joints produced with several process parameters. The following conclusions were drawn from the results. Tensile properties of friction stir welding exhibited ultimate tensile strengths of $250-270 \mathrm{MPa}$ and elongations at $4-6 \%$. Microhardness profiles were similar for all joints. The effect of post-welding heat treatment was to double the ductility of friction stir welds.

Mainly the simulation is used for temperature distribution and tensile properties can be identified. The latest developments in the numerical analysis of friction stir welding processes are microstructures of friction stir welded joints and the properties of friction stir welded structures. Some important numerical issues such as materials flow modeling, meshing procedure and failure criteria are discussed. [6] Numerical analysis of friction stir welding will allow many different welding processes to be simulated in order to understand the effects of changes in different system parameters before physical testing, which would be time-consuming or prohibitively expensive in practice. The simulation software used for numerical analysis is Deform 3D. In this paper Aluminum 2024-T3 material, $4.89 \mathrm{~mm}$ thick is considered.[7] investigated Computational Fluid Dynamics (CFD) based on modified three-dimensional model was developed to predict the distribution of temperature during lap FSW of dissimilar aluminum alloys AA2024 and AA7075. Volume of fluid approach was used and the lap FSW process was modelled as a steady-state visco-plastic turbulent flow of a rotating tool. The experimental records of transient temperature at several specific locations were used for checking the temperature field gained by numerical simulation. The temperature distribution, variations in temperature and thermal history of the processed zone were investigated. Results indicate that there is an obvious asymmetric temperature distribution between the advancing side (AS) and the retreating side (RS). The temperature of the observation points raised rapidly but decreased slowly. In particular, the temperature distribution was not continuous due to the difference of the material properties. [8] stated that results of a finite element simulation of the rolling of cylindrical work 
pieces by using the DEFORM 3D software package are presented. The curve of the limiting plasticity of L63 brass that corresponds to various schemes of the state of stress in a work piece is plotted. The deformation paths of the characteristic regions in a rolled part are calculated. [9] explained temperature distributions in a workpiece during a friction stir welding (FSW) process involving the butt joining of aluminum 6061-T6 using thermocouples . Regression analyses by the least squares method are used to predict the temperatures at the joint line. From the regression analysis results it is known that the temperatures inside the pin can be regarded as a uniform distribution and that the heat transfer starts from the rim of the pin to the edge of the workpiece. The appropriate temperatures for a successful FSW process are in between 365 and $390{ }^{\circ} \mathrm{C}$. The temperatures on the advancing side are slightly higher than those on the retreating side.

\section{Experimental Work}

Friction stir welding machine tool is a vertical axis NC-3T milling machine with an attachment of work holding fixture to weld. Experimentation is then performed at different speeds and feed rates but the tool is used as same. Aluminium 5083, 6061 alloys were used. For Friction stir welding, the work pieces are prepared of desired dimensions $200 * 60 * 6 \mathrm{~mm}$ of AA 6061 and AA5083 materials. After the material preparation, plates are properly fixed on the base plate with bolts.

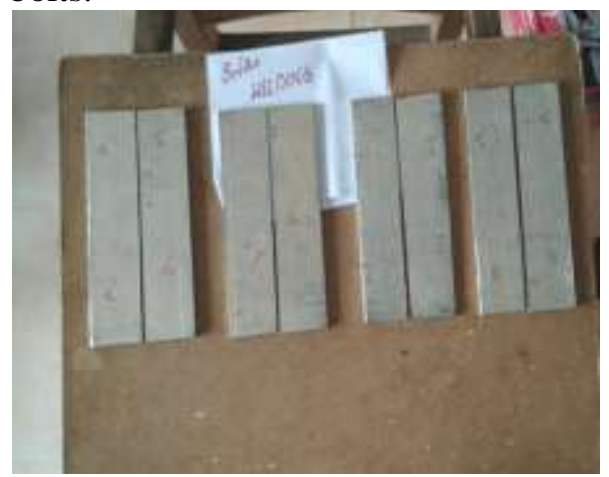

Fig. 1: Aluminium Work pieces AA6061 and 5083

The tool used in friction stir welding is taper threaded tool with taper angle of one degree. The tool is generally made of stainless steel or high speed steel. The tool is prepared on Lathe. The taper threaded cylindrical H13 steel is used for tool.

TABLE I: Chemical Composition of AA6061 and AA5083 Aluminium Alloys

\begin{tabular}{|l|l|l|l|l|l|l|l|l|l|l|}
\hline $\begin{array}{l}\text { Element } \\
\text { present }\end{array}$ & $\mathrm{Si}$ & $\mathrm{Fe}$ & $\mathrm{Cu}$ & $\mathrm{Mn}$ & $\mathrm{Mg}$ & $\mathrm{Zn}$ & $\mathrm{Tn}$ & $\mathrm{Cr}$ & $\mathrm{Al}$ & $\mathrm{Others}$ \\
\hline $\begin{array}{l}6061 \% \\
\text { Present }\end{array}$ & $0.4-0.8$ & $0-0.7$ & $.15-.4$ & $.0-.15$ & $.8-1.2$ & $.0-.25$ & 0 to .15 & $.04-.35$ & Balance & $.05-.15$ \\
\hline $\begin{array}{l}5083 \% \\
\text { Present }\end{array}$ & Max 0.4 & $0-0.7$ & Max 0.1 & $0.4-1$ & $4-4.9$ & $\begin{array}{l}\text { Max } \\
0.25\end{array}$ & $0.4-1$ & $\begin{array}{l}0.05- \\
0.25\end{array}$ & $92.4-95.6$ & 0 \\
\hline
\end{tabular}

Chromium hot-work tool steels are classified as group H13 steels by the AISI classification system. Due to its excellent combination of high toughness and fatigue resistance, H13 is used more than any other tool steel in tooling applications.

TABLE II: Chemical Composition Of Tool H13

\begin{tabular}{|l|l|l|l|l|l|l|l|}
\hline Element & $\mathrm{Cr}$ & $\mathrm{Mo}$ & $\mathrm{Si}$ & $\mathrm{V}$ & $\mathrm{Mn}$ & $\mathrm{P}$ & $\mathrm{S}$ \\
\hline Content $(\%)$ & $4.75-5.5$ & $1.1-1.75$ & $0.8-1.20$ & $0.8-1.20$ & $0.8-1.20$ & .03 & .03 \\
\hline
\end{tabular}

Now resetting is to be done in such a way that the tool alignment should be parallel to the work piece joining. After resetting of work piece, we should check once whether the tool is parallel to work piece by aligning the tool along the work piece. If it is not parallel to work piece, the weld will not be formed properly, it may align into another direction. The tool path can be checked by placing of the tool $2 \mathrm{~cm}$ above work piece. After welding, the samples were divided into three specimens for testing purpose. The impact resistance by using izod impact 
testing machine with sudden loads. Surface roughness value is measured by using Talysurf instrument on the aluminium welded pieces. The less the surface roughness value, the more will be the surface finish. In this experiment tensile strength, elongation, percentage of elongation and strain from tensile test are determined by using universal testing machine. In Tensile testing, load is applied gradually until failure occurs. From that load the tensile strength is calculated and also from the failure elongated specimen, the strain and percentage of elongation is calculated. For this tensile testing, Universal Testing Machine is used to calculate stress, strain and percentage of elongation values. Brinell hardness value can be measured by using brinell hardness testing machine, a brinell microscope having two cross wires, one is horizontal cross wire and another one is vertical cross wire. One will be taken as horizontal diameter $\mathrm{d} 1$ and the another reading will be taken as $\mathrm{d} 2$ and the average value of two diameters $\mathrm{d} 1$ and $\mathrm{d} 2$ is the diameter $\mathrm{d}$.

$$
\mathrm{BHN}=\frac{2 \mathrm{P}}{\left.\Pi \mathrm{D}\left(\mathrm{D}-\sqrt{\mathrm{D}^{2}-\mathrm{d}^{2}}\right)\right)}
$$

\section{Experimentation Results}

Experimentation Results are placed in the tabular form as below:

TABLE III: Experimentation Results

\begin{tabular}{|c|c|c|c|c|c|c|c|c|}
\hline S.No & Material & $\begin{array}{l}\text { Speed } \\
\text { Rpm }\end{array}$ & $\begin{array}{l}\text { Feed } \\
\mathrm{mm} / \mathrm{min}\end{array}$ & $\begin{array}{l}\text { Tensile } \\
\text { strength= } \\
\text { Load/area }\end{array}$ & $\begin{array}{l}\text { \%of } \\
\text { elongation }\end{array}$ & B.H.N & $\begin{array}{l}\text { Impact } \\
\text { resistance of the } \\
\text { work piece }\end{array}$ & $\begin{array}{l}\text { Ra } \\
\mu \mathbf{m}\end{array}$ \\
\hline 1 & \multirow{6}{*}{$\begin{array}{l}\text { AA6061- } \\
\text { AA6061 }\end{array}$} & 800 & 20 & 130.80 & 1.8 & 50.81 & 12.20 & 12.23 \\
\hline 2 & & 800 & 30 & 129.43 & 0.9 & 48.73 & 16.27 & 4.86 \\
\hline 3 & & 1000 & 20 & 92.65 & 2.8 & 45.50 & 18.98 & 3.30 \\
\hline 4 & & 1000 & 30 & 141.70 & 3.7 & 51.75 & 23.60 & 3.47 \\
\hline 5 & & 1200 & 20 & 143.06 & 6.3 & 49.80 & 24.47 & 3.28 \\
\hline 6 & & 1200 & 30 & 158.05 & 4.3 & 51.75 & 21.69 & 1.61 \\
\hline 7 & \multirow{6}{*}{$\begin{array}{l}\text { AA5083 } \\
\text { AA5083 }\end{array}$} & 800 & 05 & 238.43 & 8.1 & 89.44 & 25.76 & 4.96 \\
\hline 8 & & 800 & 10 & 193.47 & 6.3 & 76.52 & 29.82 & 6.43 \\
\hline 9 & & 1000 & 05 & 232.98 & 6.4 & 92.74 & 14.91 & 3.26 \\
\hline 10 & & 1000 & 10 & 140.33 & 3.5 & 83.88 & 13.55 & 2.15 \\
\hline 11 & & 1200 & 05 & 121.26 & 2.6 & 73.05 & 16.27 & 7.51 \\
\hline 12 & & 1200 & 10 & 194.83 & 6.3 & 80.69 & 18.10 & 8.13 \\
\hline 13 & \multirow{6}{*}{$\begin{array}{l}\text { AA6061- } \\
\text { AA5083 }\end{array}$} & 800 & 05 & 143.06 & 4.76 & 53.91 & 10.4 & 5.62 \\
\hline 14 & & 800 & 10 & 136.25 & 4.76 & 52.02 & 8.5 & 3.85 \\
\hline 15 & & 1000 & 05 & 129.43 & 5.50 & 57.90 & 13.1 & 4.65 \\
\hline 16 & & 1000 & 10 & 122.62 & 4.58 & 53.07 & 15.8 & 2.33 \\
\hline 17 & & 1200 & 05 & 111.75 & 3.80 & 52.02 & 15.8 & 4.73 \\
\hline 18 & & 1200 & 10 & 117.17 & 5.71 & 51.02 & 29.3 & 1.71 \\
\hline
\end{tabular}

\subsection{Tensile Test:}

As observed from tensile test on AA5083, the tensile strength will be higher at low speed and low feed rate. It is also observed that the tensile on AA6061alloy has tensile strength is 158.05 is at speed of $1200 \mathrm{rpm}$ and feed rate of $30 \mathrm{~mm} / \mathrm{min}$. For AA5083, the tensile strength value is 238.43 at speed of $800 \mathrm{rpm}$ and feed rate of 5 $\mathrm{mm} / \mathrm{min}$. It is observed that the AA5083 has more tensile strength than AA6061 in the above recorded values. From the dissimilar joints it is observed that the highest tensile strength of 143.06 was obtained at $800 \mathrm{rpm}$ and $05 \mathrm{~mm} / \mathrm{min}$ feed rate. 


\subsection{Percentage of Elongation:}

At breaking point percentage of elongation is calculated by using tensile test results. By observing the values from tensile test, the strain produced on the AA6061 is low when it has low operating speed and high feed rate among the recorded values. For AA5083, the strain produced is low for high operating speed and low feed rate among the recorded values. For dissimilar joints the low strain was produced at high speed and low feed. It is observed that the less strain produced among welded AA6061 whose value is 0.009 at $800 \mathrm{rpm}$ and at a feed rate of $30 \mathrm{~mm} / \mathrm{min}$ and also less strain produced among welded AA5083 is 0.026 at $1200 \mathrm{rpm}$ and $5 \mathrm{~mm} / \mathrm{min}$. For AA 6061 - AA5083 welding joints less strain was produced whose value is 0.038 at $1200 \mathrm{rpm}$ and at a feed rate of $05 \mathrm{~mm} / \mathrm{min}$.

\subsection{Brinell hardness test:}

By observing values from hardness test, the BHN values for AA 6061 are in the range of 45 to 55 and the BHN values for AA 5083 are in the range of 73 to 93. For the dissimilar welded joints AA6061-AA5083 hardness values in the range of 50 to $60 \mathrm{BHN}$.

\subsection{Impact resistance test:}

By observing the impact resistance values, it is concluded that the impact strength for AA6061 alloy with high speed and low feed rate is high among the recorded values and also the impact resistance for AA5083 alloy with low speed and high feed rate is high among the recorded values. It is also observed that the AA5083 has more impact strength when compared to AA6061 alloy. Form the dissimilar welded joints, it was observed that highest impact resistance occur at $1200 \mathrm{rpm}$ and at feed rate of $10 \mathrm{~mm} / \mathrm{min}$.

\subsection{Surface Roughness:}

When surface roughness values were observed that the AA6061 alloy welded at a speed $1200 \mathrm{rpm}$ and at feed rate of $30 \mathrm{~mm} / \mathrm{min}$ has less the surface roughness value was occurred which is $1.61 \mu \mathrm{m}$ and also on AA5083 alloy in the welding zone at a speed $1000 \mathrm{rpm}$ and $10 \mathrm{~mm} / \mathrm{min}$ the less surface roughness value of $2.15 \mu \mathrm{m}$ that represents more surface finish among the recorded values. Form the dissimilar joints the highest speed and highest feed having less surface roughness value so it has more surface finish.

\section{Modeling And Simulation}

Effect of tool rotational and welding speed on plastic strain is studied and insight is given on asymmetric nature of FSW process. Temperature distribution on the work piece and tool is predicted and maximum temperature is found in work piece top surface. The researchers have performed a three dimensional Finite Element Analysis (FEA) of thermal history in FSW by using Johnson-Cook material and damage models in ABAQUS/Explicit.The researchers have developed a 3D visco-plastic model of FSW to estimate temperature history and Material flow and validated the same with experimental data. They have assumed the material as a non-Newtonian fluid and allowed the flow stress to vary as a function of Temperature and strain rate. The recommended sequence for designing a manufacturing process using DEFORM 3D ,the defined proposed process, Is final forged part geometry, Material ,Tool progressions Starting workpiece/billet geometry, Processing temperatures, reheats, etc. To we have to gather the required Material data, Processing condition data, Using the DEFORM pre-processor, input the problem definition for the first operation, and submit the data for simulation, Using the DEFORM post-processor, review the results, and repeat the pre-process-simulate- review sequence for each operation in the process, If the results are unacceptable, we have to use engineering experience and then judgment is given to modify the process and then simulation sequence is repeated. For importing the geometry of Tool and Workpiece initially we have to draw the sketches. Sketches are done by using CATIA V5 R20 according to our dimensions i.e. $60 \mathrm{~mm} * 6 \mathrm{~mm} * 100 \mathrm{~mm}$ for work piece. For Tool, the dimensions are as follows- shoulder diameter of $20 \mathrm{~mm}$, shoulder length of $46 \mathrm{~mm}$, tool pin upper diameter of $6 \mathrm{~mm}$, and tool pin lower diameter of $3 \mathrm{~mm}$. With these diameters a tool is designed using catia tool. Then the catia model in .stl format is saved for importing in DEFORM 3D. 

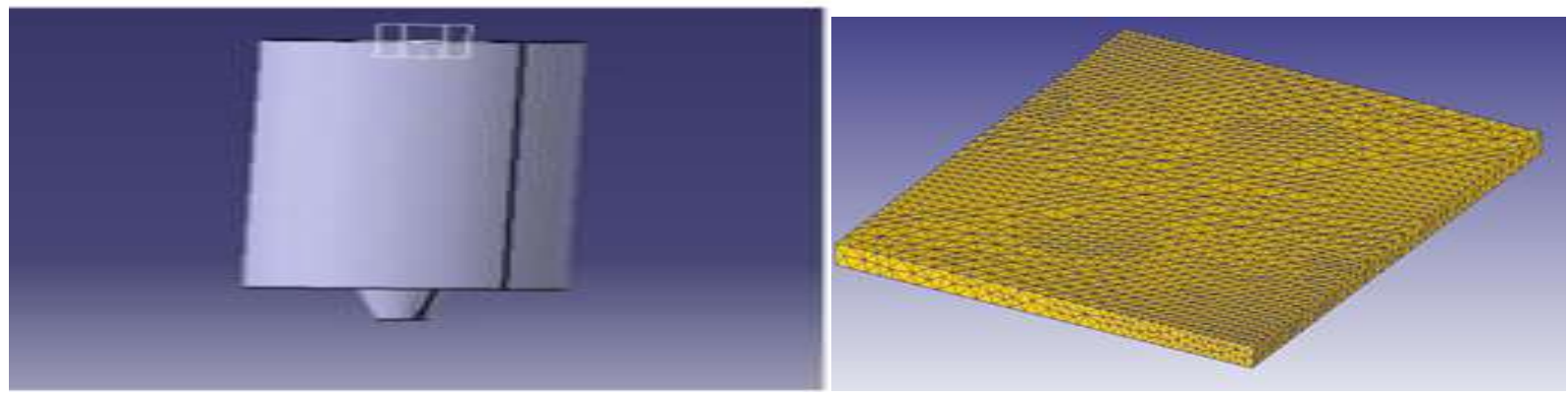

Fig.2 Catiav5.stl Modeling Tool and meshed Workpiece

Temperatures are validated for both similar and dissimilar materials. Temperatures are found for A5083 similar type, AA6061 similar type and AA5083-AA6061 dissimilar type. The process done for the manufacturing was repeated in the DEFORM -3D.

\section{Simulation Results}

Various temperatures obtained for AA5083 \& AA6061 when they were made to run at $800 \mathrm{rpm}, 1000 \mathrm{rpm}$, and $1200 \mathrm{rpm}$ at feed rates of 5, 10, 20 and $30 \mathrm{~mm} / \mathrm{min}$. These temperatures are plotted in graphical representation and they are compared between the results of manufacturing welds and DEFORM-3D tool welds
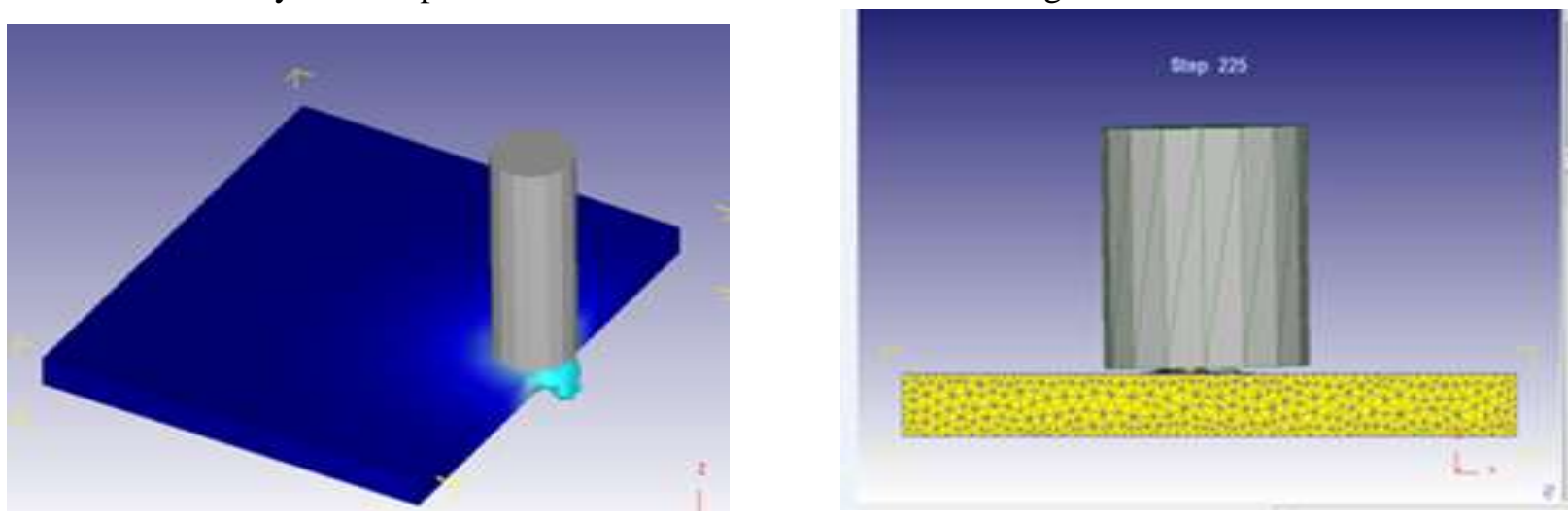

Fig. 3 During Plunging in simulation

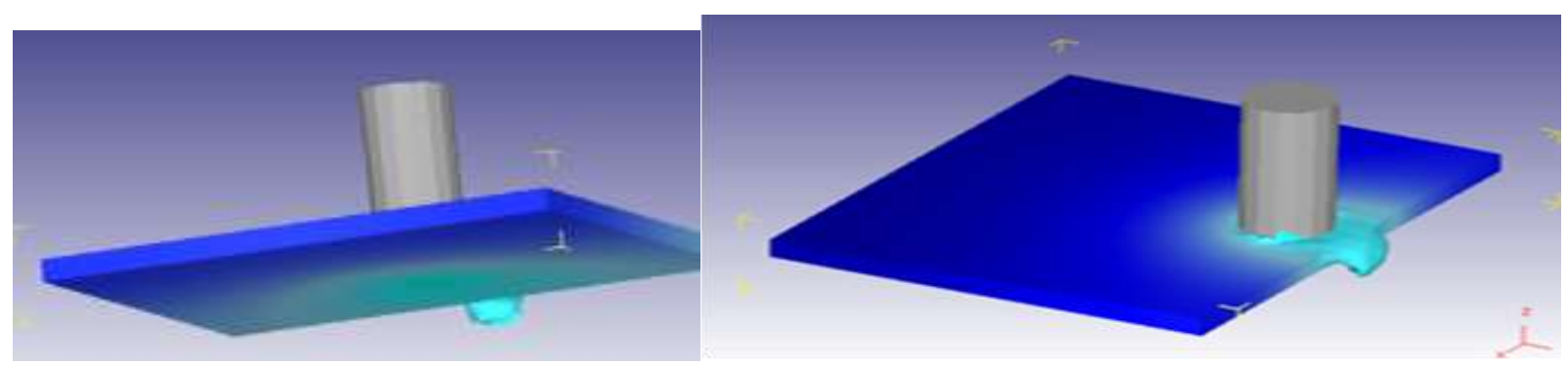

Fig.4. Welding in simulation during 


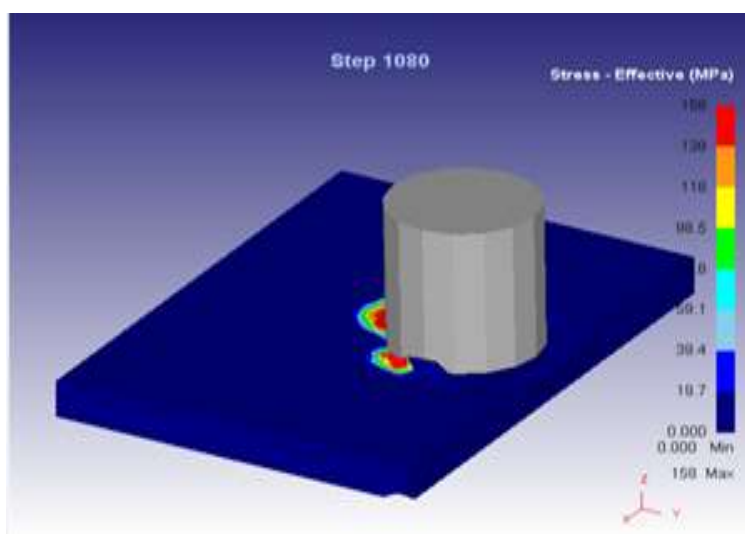

Fig. 5 Stress indications during simulation

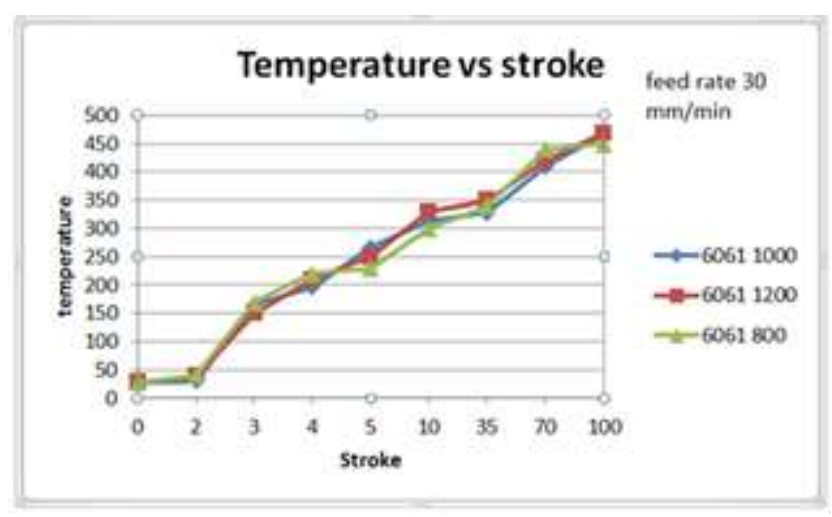

Fig. 6 Temperature raising along stroke of length of AA6061

\section{Conclusions}

In this experimental study aluminium alloys namely Al 5083 \& Al 6061 are welded using Friction Stir Welding. Welding of these alloys is carried out with different speeds such as $1200,1000,800 \mathrm{rpm}$. The parameters such as speed and feed rate are varied to obtain optimum values. Their mechanical properties such as tensile strength, hardness, impact resistance and surface roughness are investigated. Based on the results obtained, the following are the conclusions. For AA5083-6061 the best magnitude of tensile strength i.e. 143.06 $\mathrm{N} / \mathrm{mm}^{\wedge} 2$ was obtained at a speed of $800 \mathrm{rpm}$ and feed rate of $05 \mathrm{~mm} / \mathrm{min}$. The best magnitude of hardness i.e. $53.91 \mathrm{BHN}$ was obtained at a speed of $800 \mathrm{rpm}$ and feed rate of $05 \mathrm{~mm} / \mathrm{min}$. The best magnitude of impact resistance i.e. $29.3 \mathrm{~N}-\mathrm{m}$ was obtained at a speed of $1200 \mathrm{rpm}$ and feed rate of $10 \mathrm{~mm} / \mathrm{min}$. The best magnitude of surface roughness i.e. $1.71 \mu \mathrm{m}$ was obtained at a speed of $1200 \mathrm{rpm}$ and feed rate of $10 \mathrm{~mm} / \mathrm{min}$. Moreover the obtained results are validated using DEFORM-3D simulation software and the temperature results are represented in the form of graphical representation. The results are validated according to the temperatures as parameters. With FSW dissimilar metals can be easily joined with sound results. When compared Tensile strength and hardness with base material an average of $60 \%$ of the properties is obtained for similar welded joints.

\section{Acknowledgement}

Thanks to DST Project SB/FTP/ETA-284/2012

\section{References}

[1] Sadeesh P, VenkateshKannan M, Rajkumar V, Avinash P, Arivazhagan N, devendranathRamkumar K and Narayanan S "Studies on friction stir welding of AA 2024 and AA 6061 dissimilarmetals" Procedia Engineering 75 ( 2014 ) 145 $-149$

https://doi.org/10.1016/j.proeng.2013.11.031

[2] M. Koilraj , V. Sundareswaran , S. Vijayan , S.R. KoteswaraRao, "Friction stir welding of dissimilar Aluminium alloys AA2219 to AA5083 Optimization of process parameters using Taguchi technique", Materials and Design 42 (2012) $1-7$

https://doi.org/10.1016/j.matdes.2012.02.016

[3] P.M.G.P. Moreira, T. Santos, S.M.O. Tavares, V. Richter-Trummer, P. Vilaça, P.M.S.T. de Castro "Mechanical and metallurgical characterization of friction stir welding joints of AA6061-T6 with AA6082-T6" Materials and Design 30 (2009) 180-187

https://doi.org/10.1016/j.matdes.2008.04.042 
[4] Indira rani m, marpu r. N and a. C. S. Kumar"a study of process parameters of friction stir welded aa 6061 aluminum alloy in o and t6 conditions "arpn journal of engineering and applied sciencesvol. 6, no. 2, february 2011

[5] Emanuela Cerri, Paola Leo "Influence of high temperature thermal on grain stability and mechanical properties of medium strength aluminium alloys friction stir welds "Journal of Materials Processing Technology 213 (2013) 75-83 https://doi.org/10.1016/j.jmatprotec.2012.09.001

[6] Xiaocong He, Fengshou Gu, , Andrew Ball “ A Review of Numerical Analysis of Friction Stir Welding,” Progress in Materials Science 65 (2014), 1-66 https://doi.org/10.1016/j.pmatsci.2014.03.003

[7] Jingming Tang, Yifu Shen "Numerical simulation and experimental investigation of friction stir lap welding between aluminum alloys AA2024 and AA7075" Volume 666 (2016) 493-500

[8] V. N. Vostrov and P. V. Kononov, "Finite-Element Simulation of Flanging in the Deform 3D Software Package" Russian metallurgy (2016) vol 5 74-81

https://doi.org/10.1134/s0036029516050141

[9] Yeong-Maw Hwanga,, Zong-Wei Kanga, Yuang-Cherng Chioua, Hung-Hsiou Hsu "Experimental study of Temperature distribution with in work piece during friction stir welding of aluminium alloys" International Journal of Machine Tools \& Manufacture 48 (2008) 778-787

https://doi.org/10.1016/j.ijmachtools.2007.12.003

[10] Rahul Jain, SurjyaKanta Pal, Shiv Brat Singh,"Finite Element Simulation of Temperature and Strain Distribution during Friction Stir Welding of AA2024 Aluminium Alloy”, Journal of Manufacturing Process vol 442 (2016) 